\title{
Erythritol production on wheat straw using Trichoderma reesei
}

\author{
Birgit Jovanović, Robert L Mach and Astrid R Mach-Aigner*
}

\begin{abstract}
We overexpressed the err1 gene in the Trichoderma reesei wild-type and in the cellulase hyperproducing, carbon catabolite derepressed strain Rut-C30 in order to investigate the possibility of producing erythritol with T. reesei. Two different promoters were used for err 1 overexpression in both strains, a constitutive (the native pyruvat kinase ( $p k i$ ) promoter) and an inducible one (the native $\beta$-xylosidase (bx/1) promoter). The derived recombinant strains were precharacterized by analysis of err 1 transcript formation on D-xylose and xylan. Based on this, one strain of each type was chosen for further investigation for erythritol production in shake flasks and in bioreactor experiments. For the latter, we used wheat straw pretreated by an alkaline organosolve process as lignocellulosic substrate. Shake flask experiments on D-xylose showed increased erythritol formation for both, the wild-type and the Rut-C30 overexpression strain compared to their respective parental strain. Bioreactor cultivations on wheat straw did not increase erythritol formation in the wild-type overexpression strain. However, err1 overexpression in Rut-C30 led to a clearly higher erythritol formation on wheat straw.
\end{abstract}

Keywords: Erythritol; Erythrose reductase; Trichoderma reesei; Wheat straw; Lignocellulose

\section{Introduction}

Erythritol is a four-carbon sugar alcohol, which is applied as flavor enhancer, formulation aid, humectant, stabilizer, thickener, and as low-calorie sweetener, of which the latter is the main utilization. Compared with other polyols yielding about $2 \mathrm{cal} / \mathrm{g}$, erythritol yields only up to $0.2 \mathrm{cal} / \mathrm{g}$, which is due to the fact that erythritol does not undergo systemic metabolism in the human body but is excreted unchanged in the urine (Moon et al. 2010). Additionally, as a small molecule, it is easily absorbed already in the upper intestine and therefore, causes less digestive distress than other sweeteners (Livesey 2001). Since erythritol is not assimilated by Streptococcus mutans it is non-cariogenic. Furthermore it has some favorable physical and chemical properties: it is thermally stable (no decomposition or colorization at $200^{\circ} \mathrm{C}$ for $1 \mathrm{~h}$ ), better crystallizeable than sucrose, and less hygroscopic (Kasumi 1995). The negative enthalpy of solution leads to a cooling effect when dissolved. The sweetness of erythritol is plain with very weak after-taste. In a $10 \%(\mathrm{w} / \mathrm{v})$ solution it has $60-80 \%$ the

${ }^{*}$ Correspondence: astrid.mach-aigner@tuwien.ac.at

Department for Biotechnology and Microbiology, Institute of Chemical

Engineering, Vienna University of Technology, Gumpendorfer Str. 1a, A-1060 Wien, Austria sweetness of sucrose. It has a natural occurrence in several foods including beer, sake, wine, soy sauce, water melon, pear, and grape. The tolerance of erythritol by animals and humans was intensively studied (Munro et al. 1998). No adverse toxicological effects were observed. Also no carcinogenic, mutagenic or teratogenic potential or effects on fertility could be detected. Therefore, erythritol is a sugar substitute with a growing market and optimization of its production remains an issue.

Current biotechnological production of erythritol use osmophilic yeasts like Aureobasidium sp., Trichosporonoides sp., Torula sp., and Candida magnoliae. As substrate a highly concentrated glucose (typically $40 \%$ $(w / v))$ solution is applied, which is gained from chemically and enzymatically hydrolyzed wheat- and cornstarch. The hydrolyzed starch serves as carbon source and causes a high osmotic pressure that pushes the yeast to produce the osmolyte erythritol (Moon et al. 2010). Although these processes reach $40 \%(\mathrm{w} / \mathrm{w})$ yields of D-glucose to erythritol conversion, they depend on D-glucose as starting material. With regard to (socio)economical issues, starch-derived D-glucose is not a preferable substrate. Therefore, it would be an interesting alternative to use

\section{是 Springer}

(C) 2014 Jovanović et al.; licensee Springer. This is an Open Access article distributed under the terms of the Creative Commons Attribution License (http://creativecommons.org/licenses/by/2.0), which permits unrestricted use, distribution, and reproduction in any medium, provided the original work is properly credited. 
organisms that can utilize non-food, lignocellulosic biomass for the production of erythritol.

In a previous work (Jovanovic et al. 2013) we characterized the erythrose reductases (Err1) from the filamentous ascomycota Trichoderma reesei (telemorph Hypocrea jecorina (Kuhls et al. 1996)), Aspergillus niger, and Fusarium graminearium (telemorph Gibberella zeae), which are all very potent degraders of biomass. It turned out that the Err1 of $T$. reesei and $A$. niger showed comparable activities, whereas the Err1 from $F$. graminearium had a considerably lower activity (Jovanovic et al. 2013). In the present study we focused on the potential of producing erythritol in $T$. reesei from lignocellulosic biomass. The native lignocellulose-degrading enzymes of the fungus have already broad application in industry, i.e. in pulp and paper (Buchert et al. 1998; Noé et al. 1986; Welt and Dinus 1995), food and feed (Galante et al. 1993; Lanzarini and Pifferi 1989; Walsh et al. 1993), and textile industries (Koo et al. 1994, Kumar et al. 1994, Pedersen et al. 1992) as well as in biofuel production (Hahn-Hägerdal et al. 2006; Himmel et al. 2007; Ragauskas et al. 2006). As such a strong producer of cellulases and hemicellulases (a genome-wide search using the JGI Genome Portal (http://genome.jgipsf.org/Trire2/Trire2.home.html) revealed for T. reesei 10 celluloytic and 16 xylanolytic enzyme-encoding genes (Martinez et al. 2008)) it is likely that $T$. reesei is able to grow on cheap biowaste material like wheat straw as the sole carbon source. This is supported by former reports on T. reesei capable of growing on lignocellulosic material (Acebal et al. 1986; Dashtban et al. 2013).

In this study we used wheat straw that was pretreated by an alkaline organosolve process (Fackler et al. 2012) to remove the lignin up to a residual concentration of about $1 \%(\mathrm{w} / \mathrm{w})$, which makes the cellulose and hemicellulose more easily accessible for the fungus. We investigated a T. reese $i$ wild-type strain and the strain Rut-C30. Rut-30 is a cellulase hyperproducing, carbon catabolite derepressed mutant (Montenecourt and Eveleigh 1979), which is the parental strain of most industrially used $T$. reese $i$ strains (Peterson and Nevalainen 2012; Derntl et al. 2013). In both strains the errl gene was overexpressed using either the native, constitutive promoter from the pyruvate kinase encoding gene ( $p k i)$ or the native, inducible promoter from the $\beta$-xylosidase 1 encoding gene $(b x l 1)$. The overexpression strains were screened for enhanced err 1 transcript formation and the best ones where then cultivated on D-xylose and wheat straw for investigating their erythritol production capacity.

\section{Materials and methods}

\section{Strains and cultivation conditions}

The T. reesei strains QM6a $\Delta$ tmus53 (Steiger et al. 2011) and Rut-C30 (ATCC 56765), which was derived from the wild-type strain QM6a by one UV-light and two
N-methyl-N'-nitro-N-nitrosoguanidine mutation steps (Montenecourt and Eveleigh 1979), were maintained on $3 \%$ malt extract (MEX) agar. The recombinant $T$. reesei strains QPEC1, QBEC2, RPEC1, and RBEC2 generated during this study, were maintained on MEX agar containing $250 \mu \mathrm{l} / \mathrm{l}$ hygromycin B (Merck, Darmstadt, Germany).

Purification of transformed strains by streak out of spores was done on MEX agar containing $250 \mu \mathrm{l} / \mathrm{l}$ hygromycin B and $500 \mu \mathrm{l} / \mathrm{l} \mathrm{IGEPAL}^{\odot} \mathrm{CA}^{\circ} 630$ (SigmaAldrich, St. Louis, MO, USA).

Cultivation in shake flasks was performed in 250-mlErlenmeyer flasks containing $50 \mathrm{ml}$ Mandels-Andreotti (MA) medium (Mandels 1985) supplemented with $1 \%$ $(\mathrm{w} / \mathrm{v})$ D-xylose or $1 \%(\mathrm{w} / \mathrm{v})$ birch-wood xylan. For inoculation $10^{9}$ conidia per liter were used. Growth conditions were $\mathrm{pH} 5,30^{\circ} \mathrm{C}$, and $160 \mathrm{rpm}$ shaking rate. Mycelia and supernatant were seperated by filtration. For short-term storage, harvested mycelia were shockfrozen and kept in liquid nitrogen, supernatants were kept at $-20^{\circ} \mathrm{C}$.

\section{Plasmid construction}

The err1 gene and the promoter region of $b x l 1$ (1.5 kbp upstream $b x l 1, \mathrm{p} b x l 1$ ) from $T$. reesei were amplified from cDNA, which was generated as described below in the according section. Primers were used to introduce restriction sites adjacent to the gene. Primer sequences are given in Table 1. The PCR product was subcloned into PJET-1.2 (Thermo Scientific, Waltham, MA, USA), using chemically competent Escherichia coli TOP 10 (Invitrogen, Life Technologies Ltd, Paisley, UK) for plasmid replication.

For the construction of $\mathrm{pBJ}$-PEC1 the vector $\mathrm{pRLM}_{\text {ex30 }}$ (Mach et al. 1994), which contains the hph gene flanked by the $p k i$ promoter ( $p k k i)$ and the $c b h 2$ terminator, was used. The $h p h$ gene was removed by $N s i \mathrm{I} / \mathrm{XbaI}$ digestion and subsequently, err 1 that was excised from pJET-1.2 also by $N s i \mathrm{I} / \mathrm{Xba \textrm {I }}$ digestion, was inserted.

For the construction of $\mathrm{pBJ}-\mathrm{BEC} 2 \mathrm{p} p k i$ was excised from $\mathrm{pBJ}-\mathrm{PEC} 1$ with $\mathrm{XhoI} / \mathrm{XbaI}$ digestion and replaced by $\mathrm{p} b x l 1$, excised from $\mathrm{pJET}-1.2$ with $\mathrm{Sal \textrm {I }} / \mathrm{Xba \textrm {I }}$ digestion.

\section{Protoplast transformation}

For QM6a $\Delta$ tmus53 protoplast transformation was performed as described in (Gruber et al. 1990). $5 \mathrm{~g}$ of either $\mathrm{pBJ}-\mathrm{PEC} 1$ or $\mathrm{pBJ}-\mathrm{BEC} 2$ and $1 \mu \mathrm{g}$ pAN7, which confers hygromycin B resistance (Punt et al. 1987), were co-transformed into the fungal genome.

\section{Biolistic transformation}

Rut-C30 was transformed with the Biolistic ${ }^{\oplus}$ PDS-1000/He Particle Delivery System (Bio-Rad Laboratories, Hercules, CA, USA) according to a modified protocol originally described in (Te'o et al. 2002). $5 \mu \mathrm{g}$ of either pBJ-PEC1 or $\mathrm{pBJ}-\mathrm{BEC} 2$ and $1 \mu \mathrm{g}$ pAN7, which confers hygromycin B 
Table 1 Oligonucleotides used during the study

\begin{tabular}{|c|c|c|}
\hline Name & Sequence $\left(5^{\prime}-3^{\prime}\right)$ & Usage \\
\hline pbxl1_Sall_EcoRI_f & ATATAGTCGACGAATTCAGCTTGTCTGCCTTGATTACCATCC & Vector construction \\
\hline pbxl1_Xbal_r & ATATATCTAGATGCGTCCGGCTGTCCTTC & Vector construction \\
\hline err1_Xbal_f & ATATATCTAGAATGTCTTCCGGAAGGACC & Vector construction \\
\hline err1_Nsi_r & TATATATGCATITACAGCTTGATGACAGCAGTG & Vector construction \\
\hline ppki_f & GCACGCATCGCCTTATCGTC & PCR test \\
\hline qerr1_f & CTTACCATTGAGCACCTCGACG & RT-qPCR \\
\hline qerr1_r & GGTCTTGCCCTGCTTCTTGG & RT-qPCR \\
\hline qact1_f & TGAGAGCGGTGGTATCCACG & RT-qPCR \\
\hline qact1_r & GGTACCACCAGACATGACAATGTTG & RT-qPCR \\
\hline qsar1_f & TGGATCGTCAACTGGTTCTACGA & RT-qPCR \\
\hline qsar1_r & GCATGTGTAGCAACGTGGTCTIT & RT-qPCR \\
\hline
\end{tabular}

resistance (Punt et al. (Punt et al. 1987)), were cotransformed into the fungal genome.

\section{DNA isolation}

Fungal genomic DNA was isolated by phenol-chloroform extraction, using a FastPrep ${ }^{\circledR}-24$ (MP Biomedicals, Santa Ana, CA, USA) for cell disruption. About $100 \mathrm{mg}$ of mycelia was transferred to $400 \mu \mathrm{l}$ DNA extraction buffer (0.1 M Tris- $\mathrm{HCl} \mathrm{pH}$ 8.0, 1.2 M NaCl, $5 \mathrm{mM}$ EDTA) and grounded with glass beads $(0.37 \mathrm{~g} 0.010 .1 \mathrm{~mm}, 0.25 \mathrm{~g}$ $1 \mathrm{~mm}, 1$ piece $3 \mathrm{~mm}$ ) using the FastPrep. Afterwards, the mixture was immediately put on $65^{\circ} \mathrm{C}$, supplemented with $9 \mu \mathrm{M}$ RNase $\mathrm{A}$, and incubated for $30 \mathrm{~min}$. Then $200 \mu \mathrm{l}$ of phenol (pH 7.9) and $200 \mu \mathrm{l}$ of a chloroformisoamyl alcohol-mixture (25:1) were added, with vigorous mixing following each addition. Phases were separated by centrifugation $\left(12000 \mathrm{~g}, 10 \mathrm{~min}, 4^{\circ} \mathrm{C}\right)$ and the aqueous phase was transferred into a new vial. DNA was precipitated by addition of the 0.7 -fold volume of isopropanol to the aqueous phase. After $20 \mathrm{~min}$ incubation at room temperature (RT) the DNA was separated by centrifugation $\left(20000 \mathrm{~g}, 20 \mathrm{~min}, 4^{\circ} \mathrm{C}\right.$ ) and washed with $500 \mu$ l ethanol (70\%). The air-dried DNA pellet was solubilised in $50 \mu \mathrm{l}$ Tris- $\mathrm{HCl}(10 \mathrm{mM}, \mathrm{pH} 7.5)$ at $60^{\circ} \mathrm{C}$.

\section{RNA isolation and CDNA synthesis}

RNA extraction from fungal mycelia was performed with peqGOLD TriFast ${ }^{\mathrm{Ts}}$ (peqlab, Erlangen, Germany) according to the manufacturer's procedure, using a FastPrep ${ }^{\circledR}-24$ (MP Biomedicals) for cell disruption. RNA quantity and quality were determined with a NanoDrop 1000 (Thermo Scientific). A $260 \mathrm{~nm} / 280 \mathrm{~nm}$ ratio of at least 1.8 was stipulated for further sample processing. cDNA synthesis was performed with RevertAid ${ }^{\mathrm{TM}} \mathrm{H}$ Minus First Strand cDNA Synthesis Kit (Thermo Scientific) according to the manufacturer's procedure using $0.5 \mu \mathrm{g}$ of RNA.

\section{Transcript analysis}

RT-qPCR analysis was performed in a Rotor-Gene Q cycler (Qiagen, Hilden, Germany). The qPCR amplification mixture had a total volume of $15 \mu \mathrm{l}$, containing $7.5 \mu \mathrm{l} 2 \mathrm{x}$ IQ SYBR Green Supermix (Bio-Rad Laboratories), $100 \mathrm{nM}$ forward and reverse primer, and $2 \mu \mathrm{l} \mathrm{cDNA}$ (diluted 1:100). Primer sequences are given in Table 1. As reference genes act 1 and sar 1 were used (Steiger et al. 2010). All reactions were performed in triplicates. For each gene a no-template control and a no-amplification control $(0.01 \%$ SDS added to the reaction mixture) was included in each run. The cycling conditions for act1 and err 1 comprised 3 min initial denaturation and polymerase activation at $95^{\circ} \mathrm{C}$, followed by 40 cycles of $15 \mathrm{~s}$ at $95^{\circ} \mathrm{C}$, $15 \mathrm{~s}$ at $59^{\circ} \mathrm{C}$ and $15 \mathrm{~s}$ at $72 \mathrm{~s}$. For sarl different cycling conditions were applied: $3 \mathrm{~min}$ initial denaturation and polymerase activation at $95^{\circ} \mathrm{C}$, followed by 40 cycles of $15 \mathrm{~s}$ at $95^{\circ} \mathrm{C}$, and $120 \mathrm{~s}$ at $64 \mathrm{~s}$. PCR efficiency was calculated from the Rotor-Gene Q software. Relative expression levels were calculated using the equation

$$
\text { relative transcript ratio }=E_{r}^{C_{r}} \cdot E_{t}^{-C_{t}} \cdot E_{r_{0}}^{-C_{r_{0}}} \cdot E_{t_{0}}^{C_{t_{0}}},
$$

where $E$ is cycling efficiency, $C$ is the threshold cycling number, $r$ is the reference gene, $t$ the target gene and a 0 marks the sample which is used as the reference (Pfaffl 2001).

\section{Probe preparation for Southern blot analysis}

For the probe preparation 500 ng of err 1 cDNA, $5 \mu \mathrm{l} 10 \mathrm{x}$ Klenow buffer (Thermo Scientific), and $6.5 \mu \mathrm{l} 100 \mu \mathrm{M}$ random hexamer primer (Thermo Scientific) were filled up with double distilled water $\left(\mathrm{ddH}_{2} \mathrm{O}\right)$ to a final volume of $39 \mu \mathrm{l}$ and incubated at $95^{\circ} \mathrm{C}$ for $5-10 \mathrm{~min}$. The reaction mixture was put on ice and $5 \mu \mathrm{l}$ Biotin PCR Labeling Mix (Jena Bioscience, Jena, Germany) and $1 \mu$ l Klenow fragment exo- (Thermo Scientific) were added. The mixture was filled up with $\mathrm{ddH}_{2} \mathrm{O}$ to a final volume of $50 \mu \mathrm{l}$ and incubated at $37^{\circ} \mathrm{C}$ for $24 \mathrm{~h}$. For DNA precipitation 
$10 \mu \mathrm{LiCl}(4 \mathrm{M})$ and $200 \mu \mathrm{l}$ ethanol (96\%) were added. After incubation at RT for $15 \mathrm{~min}$, at ice for $15 \mathrm{~min}$, and at $-20^{\circ} \mathrm{C}$ for $1 \mathrm{~h}$, the DNA was separated by centrifugation with $20000 \mathrm{~g}$ at $4^{\circ} \mathrm{C}$ for $30 \mathrm{~min}$. The pellet was washed with $500 \mu$ l ethanol (70\%), followed by centrifugation with $20000 \mathrm{~g}$ at $4^{\circ} \mathrm{C}$ for $10 \mathrm{~min}$. After drying the pellet at

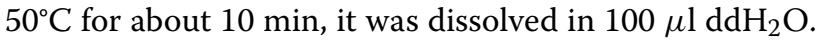
The quality of the probe was tested by agarose gel electrophoresis, and the concentration was determined with the NanoDrop 1000 (Thermo Scientific).

\section{Southern blot analysis}

For the Southern blot $15 \mu \mathrm{g}$ chromosomal DNA of each strain used in this study was digested in a triple digestion with $5 \mu \mathrm{l}$ of each NdeI, SalI, and BglII (each $10 \mathrm{U} / \mu \mathrm{l}$, Thermo Scientific), using 10x Buffer O (Thermo Scientific). The reaction mixtures were filled up with $\mathrm{ddH}_{2} \mathrm{O}$ to a final volume of $100 \mu \mathrm{l}$ and then split into $20 \mu \mathrm{l}$ aliquots for digestion at $37^{\circ} \mathrm{C}$ over night $(\mathrm{o} / \mathrm{n})$. After digestion, samples were incubated at $70^{\circ} \mathrm{C}$ for $20 \mathrm{~min}$ and the completion of digestion controlled by agarose gel electrophoresis. Digestion aliquots of each sample were pooled and concentrated to a final volume of $10-20 \mu \mathrm{l}$ and applied to a $1 \%$ agarose gel. As length standard $5 \mu \mathrm{l}$ Gene Ruler $1 \mathrm{~kb}$ DNA Ladder (Thermo Scientific) was used. Using the Mini-Sub ${ }^{\circ}$ Cell system (Bio-Rad Laboratories) the gel was run at $80 \mathrm{~V}$ for $1 \mathrm{~h}$ in TAE buffer, and afterwards incubated in $0.4 \mathrm{M} \mathrm{NaOH}$ and $0.6 \mathrm{M}$ $\mathrm{NaCl}$, and then in $0.5 \mathrm{M}$ Tris ( $\mathrm{pH} 7.5$ ) and $1.5 \mathrm{M} \mathrm{NaCl}$ for $30 \mathrm{~min}$ each. The DNA was transferred to a Biodyne B membrane (Pall Corporation, Port Washington, NY, USA) by a capillary blot with 10x saline-sodium citrate (SSC) buffer $(1.5 \mathrm{M} \mathrm{NaCl}, 0.15 \mathrm{M}$ sodium citrate, $\mathrm{pH}$ 7.2) o/n. After blotting, the membrane was incubated in $0.4 \mathrm{M} \mathrm{NaOH}$, and then in $0.2 \mathrm{M}$ Tris ( $\mathrm{pH} 7.5$ ) for 1 min each. Cross-linking was performed with a GS Gene Linker UV chamber (Bio-Rad Laboratories) using program C3 and 150 mJoule on the wet membrane. For pre-hybridization, the membrane was incubated at $65^{\circ} \mathrm{C}$ for $3 \mathrm{~h}$ in $20 \mathrm{ml}$ Southern blot hybridization buffer $(25 \%$ (v/v) 20x SSC, 10\% (v/v) 50x Denhardt's solution, 0.2\% (v/v) EDTA (0.5 M, pH 8.0), $0.05 \mathrm{M} \mathrm{NaH}_{2} \mathrm{PO}_{4}, 0.1 \%$ (w/v) SDS, $0.5 \%$ (w/v) BSA), supplemented with $100 \mu \mathrm{g} / \mathrm{ml}$ single stranded salmon sperm DNA and freshly denaturated $\left(10 \mathrm{~min}\right.$ at $\left.95^{\circ} \mathrm{C}\right)$ probe. For hybridization, the membrane was incubated at $65^{\circ} \mathrm{Co} / \mathrm{n}$ in $10 \mathrm{ml}$ Southern blot hybridization buffer. The membrane was washed twice at RT for $5 \mathrm{~min}$ in $50 \mathrm{ml} 2 \mathrm{x}$ SSC supplemented with $0.1 \%$ $(\mathrm{w} / \mathrm{v}) \mathrm{SDS}$, followed by washing twice at $65^{\circ} \mathrm{C}$ for $15 \mathrm{~min}$ with $50 \mathrm{ml} 0.1 \mathrm{x}$ SSC, supplemented with $0.1 \%$ (w/v) SDS. After incubation at RT for 10 min in Southern blot blocking solution $\left(125 \mathrm{mM} \mathrm{NaCl}, 17 \mathrm{mM} \mathrm{Na} 2 \mathrm{HPO}_{4}, 8 \mathrm{mM}\right.$ $\mathrm{NaH}_{2} \mathrm{PO}_{4}, 0.5 \%$ (w/v) SDS, pH 7.2), the membrane was incubated light-protected at RT for $30 \mathrm{~min}$ in Southern blot blocking solution supplemented with $1 \mu \mathrm{g} / \mathrm{ml}$ Dylight 650-labeled Streptavidin (Thermo Scientific). The membrane was washed 4 times light-protected at RT for $10 \mathrm{~min}$ in $50 \mathrm{ml} \mathrm{1:10} \mathrm{diluted} \mathrm{Southern} \mathrm{blocking} \mathrm{solution} \mathrm{and} \mathrm{then}$ scanned with Typhoon FLA 9500 (GE Healthcare Life Sciences, Buckinghamshire, England) set for Alexa Fluor 647 at $1000 \mathrm{~V}$.

\section{Cultivation in bioreactors}

Cultivation was performed in 2-l-bench top bioreactors (Bioengineering AG, Wald, Swiss), containing 1.31 fermentation medium $\left(\left(\mathrm{NH}_{4}\right)_{2} \mathrm{SO}_{4} 3.50 \mathrm{~g} / \mathrm{l}, \mathrm{KH}_{2} \mathrm{PO}_{4}\right.$ $5.00 \mathrm{~g} / \mathrm{l}, \mathrm{MgSO}_{4} .7 \mathrm{H}_{2} \mathrm{O} 1.25 \mathrm{~g} / \mathrm{l}, \mathrm{NaCl} 0.625 \mathrm{~g} / \mathrm{l}$, peptone from Casein $1.25 \mathrm{~g} / \mathrm{l}$, Tween $800.625 \mathrm{~g} / \mathrm{l}$ ), supplemented with $1.5 \mathrm{ml} / \mathrm{l}$ trace element solution $\left(\mathrm{FeSO}_{4} .7 \mathrm{H}_{2} \mathrm{O}\right.$ $0.90 \mathrm{mM}, \mathrm{MnSO}_{4} \cdot \mathrm{H}_{2} \mathrm{O} 0.50 \mathrm{mM}, \mathrm{ZnSO}_{4} .7 \mathrm{H}_{2} \mathrm{O} 0.24 \mathrm{mM}$, $\mathrm{CaCl}_{2} .7 \mathrm{H}_{2} \mathrm{O} 0.68 \mathrm{mM}$ ), $1.7 \%$ (w/v) wheat straw (pretreated by an alkaline organosolv process for lignin removal (Fackler et al. 2012) (Annikki, Graz, Austria)), and Antifoam Y-30 Emulsion (1 ml/bioreactor). For inoculation $10^{9}$ conidia per liter were used. Agitation rate was $500 \mathrm{rpm}$, temperature was $28^{\circ} \mathrm{C}$, and aeration rate was $0.5 \mathrm{vvm}$.

\section{GC analysis}

Mycelia from shake flask cultures were ground under liquid nitrogen. The powder was suspended in $3 \mathrm{ml}$ distilled water and sonicated using a Sonifier ${ }^{\circ} 250$ Cell Disruptor (Branson, Danbury, CT, USA) (power 70\%, duty cycle $40 \%$, power for $3 \mathrm{~min}$, on ice). Insoluble compounds were separated by centrifugation $\left(20000 \mathrm{~g}, 10 \mathrm{~min}, 4^{\circ} \mathrm{C}\right)$, the clear supernatant was used for further processing.

Supernatants from shake flask cultures were used directly for further processing.

For samples from cultivation in bioreactors $30 \mathrm{ml}$ of the whole cultivation broth were first mechanically disrupted with a potter for $1 \mathrm{~min}$, then sonicated, and afterwards centrifuged as described above for mycelia from shake flask cultures.

Sample preparation for GC was done in triplicates as follows: $300 \mu \mathrm{l}$ of the clear supernatant (prepared as described above), supplemented with 10 ng myo-inositol as internal standard, was gently mixed with $1.2 \mathrm{ml}$ ethanol (96\%) and incubated for $30 \mathrm{~min}$ at RT for protein precipitation. The precipitate was separated by centrifugation $\left(20000 \mathrm{~g}, 10 \mathrm{~min}, 4^{\circ} \mathrm{C}\right)$. Samples were dried under vacuum and thereafter silylated (50 $\mu \mathrm{l}$ pyridine, $250 \mu \mathrm{l}$ hexamethyldisilazane, $120 \mu \mathrm{l}$ trimethylsilyl chloride). For quantitative erythritol determination a GC equipment (Agilent Technologies, Santa Clara, CA, USA) with a HP-5-column (30 m, inner diameter $0.32 \mathrm{~mm}$, film $0.26 \mu \mathrm{m}$ ) (Agilent) was used. The mobile phase consisted of helium with a flow of $1.4 \mathrm{l} / \mathrm{min}$, the column temperature was as follows: $150^{\circ} \mathrm{C}$ for $1 \mathrm{~min}$, ramping $150220^{\circ} \mathrm{C}\left(\Delta \mathrm{T} 4^{\circ} \mathrm{C} / \mathrm{min}\right)$, 
ramping $220-320^{\circ} \mathrm{C}\left(\Delta \mathrm{T} 20^{\circ} \mathrm{C} / \mathrm{min}\right), 320^{\circ} \mathrm{C}$ for $6.5 \mathrm{~min}$. Detection was performed with FID at $300^{\circ} \mathrm{C}$. The retention times were determined using pure standard substances.

\section{Sodium hydroxide soluble protein (SSP)}

$2 \mathrm{ml}$ cultivation broth were centrifuged at $20000 \mathrm{~g}$ for $10 \mathrm{~min}$ at $4^{\circ} \mathrm{C}$. The supernatant was discarded and the pellet resuspended in $3 \mathrm{ml} 0.1 \mathrm{M} \mathrm{NaOH}$ before sonication with a Sonifier 250 Cell Disruptor (Branson) (power $70 \%$, duty cycle $40 \%$, power $20 \mathrm{~s}$, pause $40 \mathrm{~s}, 10$ cycles, on ice). The sonicated samples were incubated for $3 \mathrm{~h}$ at RT. After centrifugation $\left(20000 \mathrm{~g}, 10 \mathrm{~min}, 4^{\circ} \mathrm{C}\right)$ the supernatant was used to determine protein concentration with a Bradford assay. Therefore, $20 \mu$ l diluted sample (1:10 1:100) were added to $1 \mathrm{ml}$ 1:5 diluted Bradford Reagens (Bio-Rad Laboratories) and incubated for exactly $10 \mathrm{~min}$ at RT before measuring the absorption on a V-630 UVVis spectrophotometer (Jasco, Tokio, Japan) at $595 \mathrm{~nm}$. As standard bovine serum albumin in concentrations from $10-100 \mu \mathrm{g} / \mathrm{ml}$ was used.

\section{Results}

\section{Characterization of err 1 overexpression strains}

Protoplast transformation of the wild-type strain with the plasmid $\mathrm{pBJ}-\mathrm{PEC} 1$, introducing err 1 under the constitutive $p k i$ promoter of $T$. reese $i$, yielded 8 recombinant strains (named QPEC1-\#). With the plasmid pBJ-BEC2, introducing err 1 under the inducible $b x l 1$ promoter of T. reesei, 3 recombinant strains (named QBEC2-\#) were received. Biolistic transformation of Rut-C30 with the plasmid pBJ-PEC1 yielded 12 recombinant strains (named RPEC1-\#), and with the plasmid pBJ-BEC2 20 recombinant strains (named RBEC2-\#) were obtained. Stable insertion of the plasmid into the fungal genome was confirmed by isolation of genomic DNA and a following PCR amplifying a fragment including the introduced promoter and err1. After two rounds of spore streak outs, 3-7 recombinant strains of all four types were chosen for further characterization according to their growth. The selected recombinant strains were cultivated in shake flasks on D-xylose as well as birch-wood xylan followed by transcript analysis of err1. From each type, the strain with the highest transcript rate was chosen for further characterization (Figure 1). From now on strains were termed QPEC1, QBEC2, RPEC1, and RBEC2, respectively. A determination of the copy number of the newly introduced err 1 in the four finally selected recombinant strains was performed by Southern blot analysis (Figure 2). Ectopic in tandem integration, which is the most common in $T$. reesei (Mach and Zeilinger 1998), was observed in all four strains. For QPEC1 and RPEC1 more than 5 additional copies were estimated, for QBEC2 and RBEC2 1-2 additional copies were estimated.

\section{Increased production of erythritol on D-xylose}

In order to get first insight in the native erythritol formation in the parental strains and the effect of the err1 overexpression, the strains QPEC1 and RPEC1, as well as their respective parental strains, were cultivated in shake flasks. For this first experiment D-xylose was used as carbon source as all strains grow well on this carbon source, and on the other hand as the monomer of the xylan-backbone it is a main component of lignocellulose, which is aimed to be used finally. Samples were taken after biomass formation was observed and analyzed by gas chromatography (GC) for erythritol production. Separate analysis of the supernatant and the mycelia revealed that no erythritol could be found in the supernatant. The erythritol concentrations detected in the mycelia are presented in Figure 3. For the wild-type and QPEC1 we could demonstrate, that the overexpression strain contained clearly more erythritol than the parental strain, with an increase of 1.6-fold (24 h) and 3.2-fold (30 h) (Figure 3a). For Rut-C30 and RPEC1 the increase of intracellular erythritol concentration in the err 1 overexpression strain are not that explicit compared to the wild-type and to QPEC1 (Figure 3b). After $30 \mathrm{~h}$ and $36 \mathrm{~h}$ the increase in the recombinant strain is 1.2 -fold and 1.4-fold, respectively, compared to the parental strain. Compared with the wild-type, both Rut-C30 and RPEC1 contained slightly less erythritol. However, this observation was considered as a preliminary result because the advantages of using Rut-C30 are not necessarily that pronounced on D-xylose than on a lignocellulosic substrate, which finally should be used according to the aim of this study.

\section{Erythritol formation by the wild-type and its err 1 overexpression strains on pretreated wheat straw}

Experiments to investigate the growth ability on pretreated wheat straw and corresponding erythritol production on this substrate were performed by cultivation in a bioreactor starting with the wild-type strain and its respective err 1 overexpression strains, QPEC1 and QBEC2. All three strains were able to grow on wheat straw as sole carbon source, even if inoculated directly with conidia and not with pregrown fungal mycelium. Microscopic analysis of samples taken $8 \mathrm{~h}$ after inoculation already showed a high germination rate. Further microscopic samples taken during the fermentation process showed good mycelial growth, strongly branched hyphae, and disappearance of the straw, which is due to enzymatic degradation by the fungus. Samples for investigation of erythritol production were taken $48 \mathrm{~h}$ and $72 \mathrm{~h}$ after inoculation. Since the cultivation broth contained aside from the mycelia also wheat straw as insoluble compound, it was not possible to separate the mycelia for analysis. Therefore, the whole samples were analyzed for erythritol content. Sodium hydroxide soluble protein 


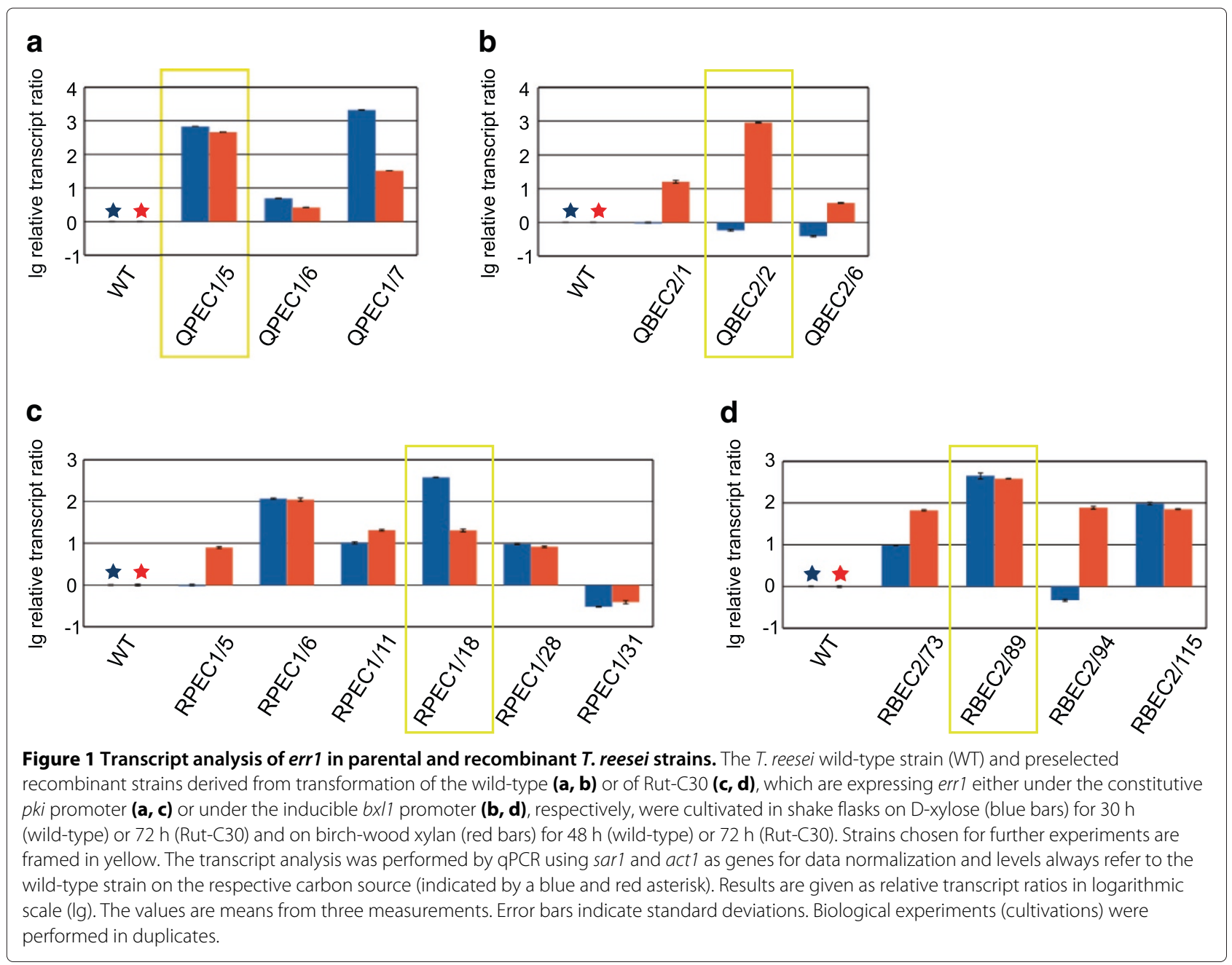

(SSP) was determined and was used as an indicator for the biomass concentration. From the SSP one can conclude that the strains have a similar growth behavior (Figure 4a). The xylanase activity was similar in the wildtype and in QBEC2, but clearly increased in QPEC1 after $72 \mathrm{~h}$ (Figure 4b). In contrast to the results from the shake flask experiments on D-xylose, no increase in production of erythritol in the recombinant strains could be found by GC analysis (Figure 4c), even though transcript analysis of err 1 showed a slight increase in the recombinant strains after $48 \mathrm{~h}$, and an even more pronounced one after $72 \mathrm{~h}$ (Figure 4d). Summarizing, these strains can grow on wheat straw and metabolize derived monosaccharides to erythritol. However, overexpression of err 1 did not enhance erythritol formation on wheat straw.

\section{Erythritol formation by Rut-C 30 and its err 1 overexpression strains on pretreated wheat straw}

As a cellulase hyperproducing strain, Rut-C30 can be expected to better utilize lignocellulosic substrates compared to the wild-type strain. Indeed, an analog experiment to the one described above, using Rut-C30 and RPEC1 showed more promising results as increased erythritol production in the overexpression strain was observed (Additional file 1). Consequently, a more extensive study drawing samples every $12 \mathrm{~h}$, starting $18 \mathrm{~h}$ after inoculation, was conducted with these strains again cultivated in a bioreactor on pretreated wheat straw. The SSP indicated an similar growth behavior for all strains, whereupon RPEC1 after $42 \mathrm{~h}$ slightly dropped behind the others (Figure 5a). The same pattern could be observed even more clearly for the xylanase activities (Figure 5b). The course of erythritol concentration is depicted in Figure 5c. One can observe that the parental strain Rut-C30 started slightly faster with erythritol formation. All strains reached their maximum erythritol production after $42 \mathrm{~h}$, whereupon the err 1 overexpression strains showed increased formation compared to their parental strain. Even though RPEC1 and RBEC2 shared nearly the same maximum erythritol concentration, they differed in their time course of production. Erythritol formation by RBEC2 rose faster in the beginning, but also 


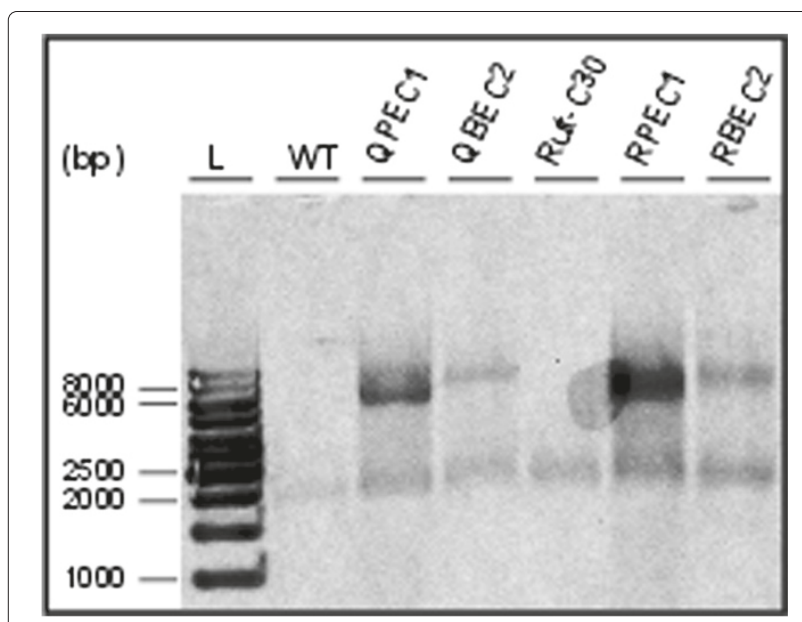

Figure 2 Southern blot analysis of parental and err 1 overexpression $T$. reesei strains. On an agarose gel Ndel/Sall/Bglll-digested DNA from the wild-type (WT) strain bearing the native $\operatorname{err} 1$ (2340 bp), the thereof derived err 1 overexpression strains QPEC1 (containing the native err 1 (2340 bp) and $n+1$ inserted fragments (5410 bp)) and QBEC2 (containing the native err 1 (2340 bp) and $\mathrm{n}+1$ inserted fragments ( $6626 \mathrm{bp}))$, Rut-C30 bearing the native $\operatorname{err} 1$ (2340 bp), and the thereof derived err 1 overexpression strains

RPEC1 (containing the native err 1 (2340 bp) and $n+1$ inserted fragments (5410 bp)) and RBEC2 (containing the native err1 (2340 bp) and $n+1$ inserted fragments ( 6626 bp)) was separated. $n$ means the band intensity in relation to the native err 1-containing band. A $1 \mathrm{~kb}$ DNA ladder (L) was used for estimation of DNA fragment size; indicated sizes are given in bp. As probe a biotin-labeled fragment containing the structural err 1 gene was used. For visualization Dylight 650-labeled streptavidin was applied and the membrane was scanned with a Typhoon FLA 9500.

dropped faster after having reached the maximum. After $66 \mathrm{~h}$ the erythritol concentration dropped for all three strains to a nearly equal level, so it seems that the overexpression of errl does not only boost the formation of erythritol but might also trigger the erythritol consumption of this storage compound when conditions (e.g. carbon source availability) become less favorable. It should also be noticed that the amount of erythritol produced by the recombinant strains was about 10 -fold higher compared to the wild-type at the peak of production. The transcript analysis showed constant expression of err1 for RPEC1 and an increasing expression for RBEC2, which is in good accordance with the type of promoters used. The expression of err 1 in the parental strain first decreased until it reaches a minimum at $42 \mathrm{~h}$ after inoculation. Afterwards, it slightly reincreased, but always remained lower than in the overexpression strains (Figure 5d).

\section{Discussion}

The by an alkaline organosolve process pretreated wheat straw (Fackler et al. 2012) used in our experiments, turned out to be a very well utilizeable substrate for $T$. reesei cultivation. In contrary to other pretreatment processes, this method does not require any chemicals or catalysts that subsequently inhibit fungal growth. The alcohol, which is used in the process as organic solvent, can be sufficiently removed by washing. The achieved removal of lignin (up to a residual share of 1\%) (Fackler et al. 2012) makes the utilizeable cellulose and hemicellulose enough accessible for the fungus so that even direct inoculation with conidia was possible with this substrate as sole carbon source.

The comparison of the recombinant strains with their respective parentals showed that the overexpression of err1 was successful an led to an increase in erythritol formation. In case of the wild-type and its recombinant strains this effect was more pronounced in shake flask cultivations on D-xylose, whereas Rut-C30 and its recombinant strains yielded better results in the bioreactor cultivation on pretreated wheat straw. Not only the relative increase of erythritol concentration in the recombinant strains compared to the parental strain was higher, but also the total amount of erythritol produced was about
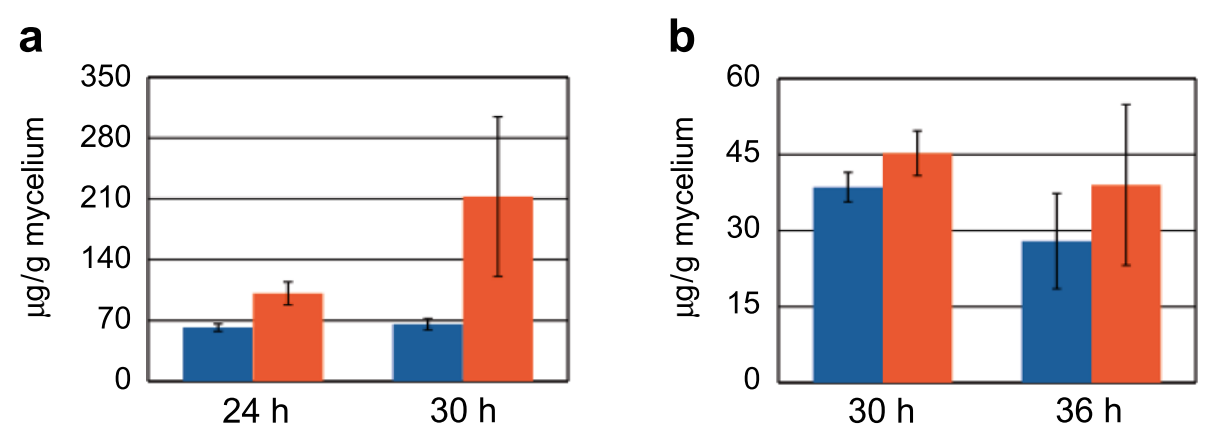

Figure 3 Erythritol production on D-xylose. The T. reesei (a) wild-type strain (blue bars) and the thereof derived err1 overexpression strain QPEC1 (red bars) as well as (b) Rut-C30 (blue bars) and the thereof derived err 1 overexpression strain RPEC1 (red bars) were cultivated in shake flasks on D-xylose. Samples were taken after the indicated time and erythritol concentration was determined by GC-analysis from cell free extracts. Biological experiments (cultivations) were performed in duplicates. Standard deviations were obtained from two biological duplicates and measurements in triplicates each. 


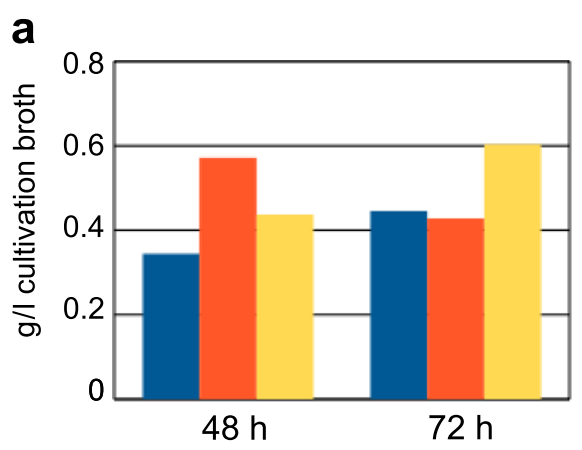

C

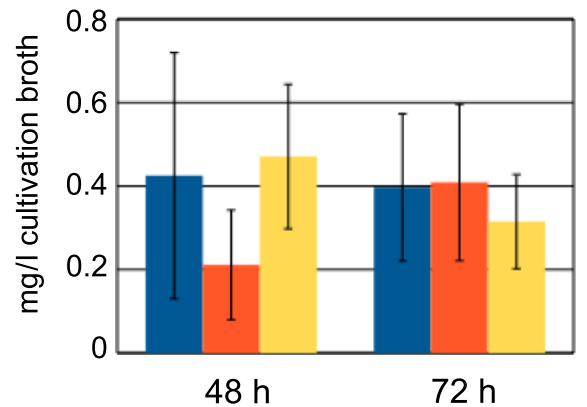

b

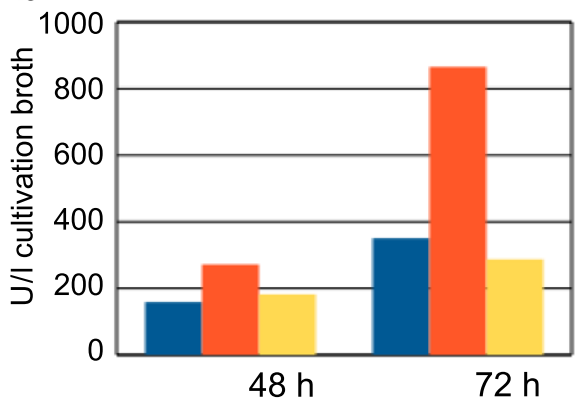

d

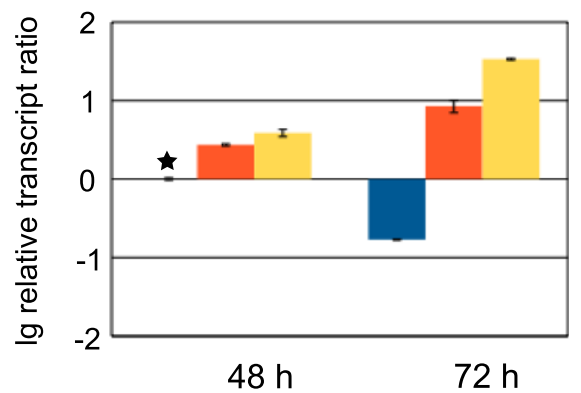

Figure 4 Cultivation of the wild-type and err1 overexpression strains on wheat straw. The T. reesei wild-type strain (blue bars), and the err 1 overexpression strains QPEC1 (red bars) and QBEC2 (yellow bars) were cultivated in bench-top bioreactors on pretreated wheat straw. Samples were taken after 48 and 72 h. (a) Sodium soluble protein concentration (given in $\mathrm{g} / \mathrm{l}$ cultivation broth) was measured in triplicates in cultivation broth samples after cell disruption to indicate biomass formation. Standard deviations were below 5\%. (b) Xylanase activity (given in U/I cultivation broth) was measured in triplicates in the cultivation supernatants. Standard deviations were below 5\%. (c) Erythritol concentration (given in mg/l cultivation broth) was measured in triplicates by GC in cultivation broth samples after cell disruption. Error bars indicate standard deviations. (d) Transcript analysis of err (given as relative transcript ratio in logarithmic scale (lg)) was performed by qPCR in triplicates using sar1 and act1 as genes for data normalization and levels always refer to the wild-type strain cultivated for $48 \mathrm{~h}$ (as indicated by an asterisk). Error bars indicate standard deviations. Biological experiments (cultivations) were performed in duplicates.

10-fold increased compared to the wild-type and its recombinant strains. This observation can be explained by the fact that Rut-C30 is a cellulase hyperproducing, carbon catabolite derepressed strain (Montenecourt and Eveleigh 1979), which makes it very likely that it better utilizes a complex substrate like wheat straw. This assumption is supported by the observed increased biomass formation and enhanced xylanase activity produced. Concerning the promoters used, the constitutive $p k i$ promoter seems to be favorable, since the erythritol production peak was slightly higher and this high level remained for a longer period ( $54 \mathrm{~h}$ ). It should be mentioned that an even higher maximum might occur between the samples taken. However, cultivation time turned out to be an important factor for the erythritol formation, since after the peak of production, the erythritol concentration drops about as fast as it rises in the beginning. Accordingly, the elimination of the back reaction can be considered as one of the main targets of further strain improvement. Since we found that in T. reesei erythritol is not exported to the media, but accumulated in the cell, presumably, the most efficient way to prevent the back reaction would be to force the fungus to secrete the erythritol. This strategy would also be favorable in consideration of the osmotic balance of the cell. Taking into account that in case of erythritol production methods using yeasts, erythritol can be found in the supernatant (see e.g. Ryu et al. 2000; Rymowicz et al. 2009; Sawada et al. 2009), in yeasts must exist a transport system for erythritol that probably can be introduced into T. reesei. Another strategy to improve erythritol formation could be to reduce the accumulation of other polyols. This would on the one hand provide additional starting material for the erythritol production, and at the same time it would prevent an additional rise of the intracellular osmotic pressure by these substances.

$\mathrm{GC}$ analysis of the cultivation broth of Rut-C30 and its recombinant strains grown on wheat straw revealed especially a high accumulation of arabinitol, but also considerable amounts of xylitol (highest concentrations measured were $696 \mathrm{mg}$ arabinitol and $63 \mathrm{mg}$ xylitol per liter fermentation broth). Both substances are metabolites in the interconversion of the pentoses derived from lignocellulose degradation (i.e. L-arabinose, D-xylose) (Figure 6). Overexpression of the L-arabinitol dehydrogenase and 


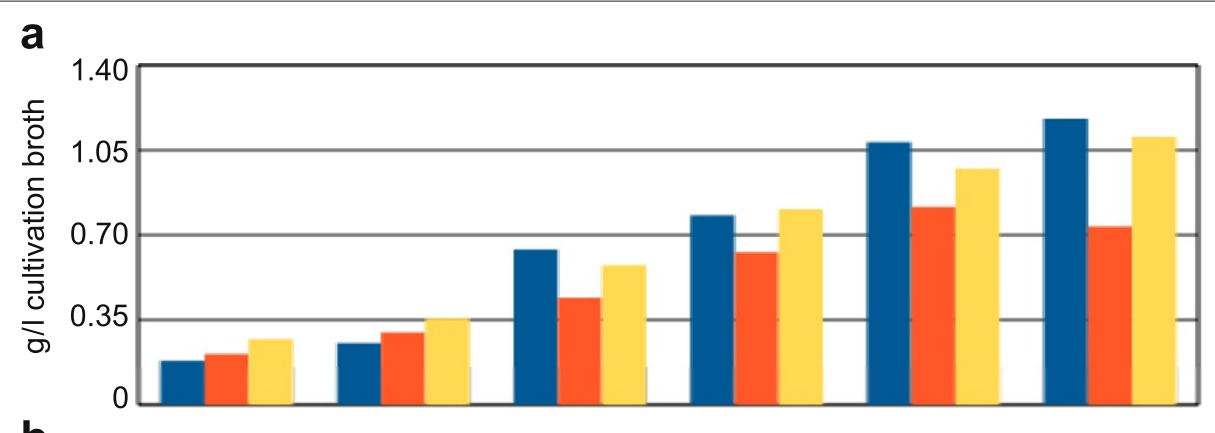

b
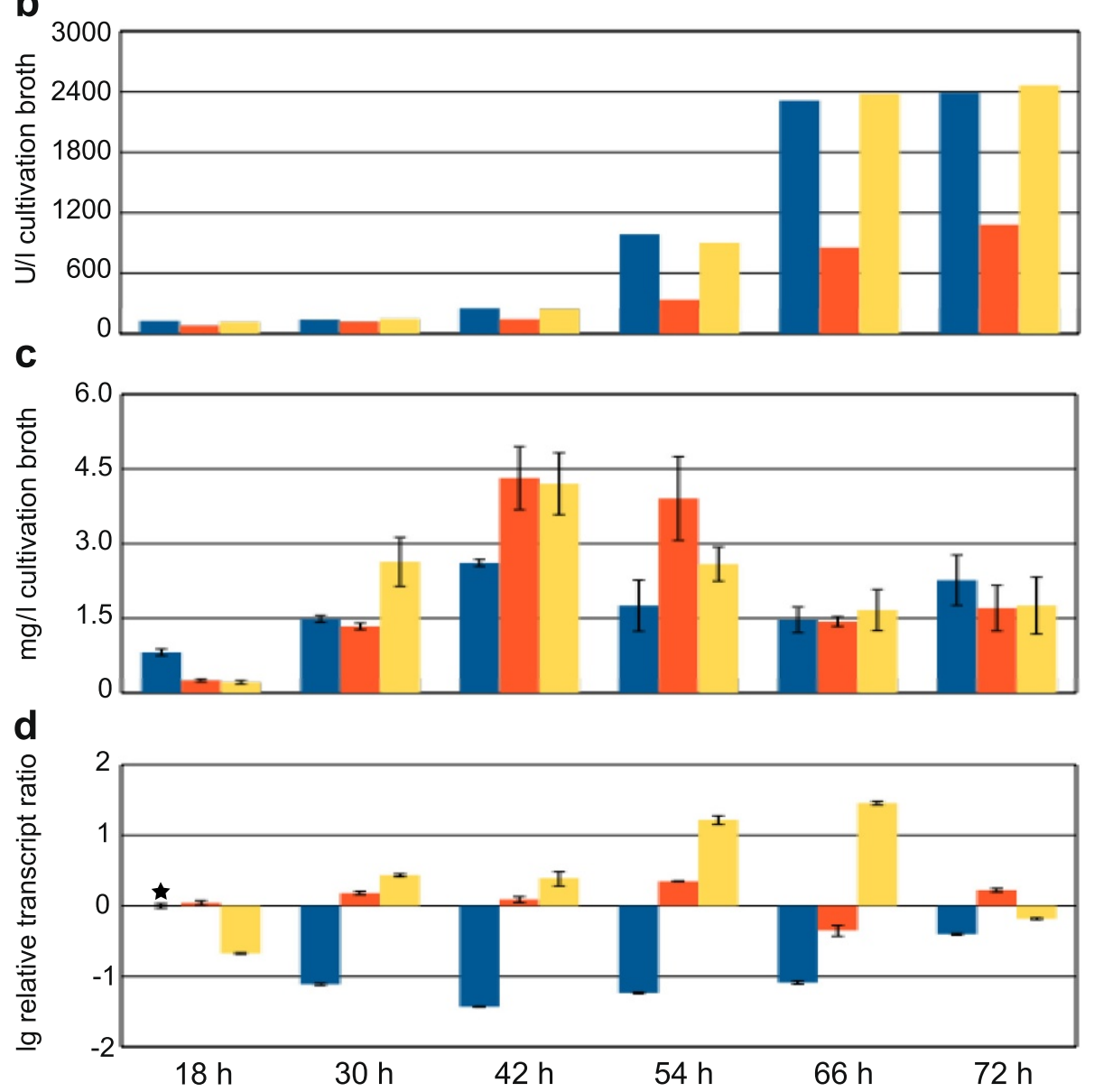

Figure 5 Cultivation of Rut-C 30 and err 1 overexpression strains on wheat straw. Rut-C30 (blue bars), and the err1 overexpression strains RPEC 1 (red bars) and RBEC2 (yellow bars) were cultivated in bench-top bioreactors on pretreated wheat straw. Samples were taken after 18, 30, 42, 54, 66, and 72 h. (a) Sodium soluble protein concentration (given in $\mathrm{g} / \mathrm{l}$ cultivation broth) was measured in triplicates in cultivation broth samples after cell disruption to indicate biomass formation. Standard deviations were below 5\%. (b) Xylanase activity (given in U/I cultivation broth) was measured in triplicates in the cultivation supernatants. Standard deviations were below 5\%. (c) Erythritol concentration (given in mg/l cultivation broth) was measured in triplicates by GC in cultivation broth samples after cell disruption. Error bars indicate standard deviations. (d) Transcript analysis of err 1 (given as relative transcript ratio in logarithmic scale (lg)) was performed by qPCR in triplicates using sarl and act1 as genes for data normalization and levels always refer to Rut-C30 cultivated for $18 \mathrm{~h}$ (as indicated by an asterisk). Error bars indicate standard deviations. Biological experiments (cultivations) were performed in duplicates.

the D-xylulose reductase in T. reesei might help here to enforce the flux of these two major substrates into the pentose phosphate pathway (PPP) and thus enhance erythritol formation, which is a side product of the PPP. Even if the amounts of erythritol produced by now in
T. reesei (approx. $5 \mathrm{mg} / \mathrm{l}$ ) do not reach the current production standards with yeasts, it must be taken into consideration, that these yeast strains are highly mutagenized, and subsequently selected for high erythritol production for many years, and production conditions 


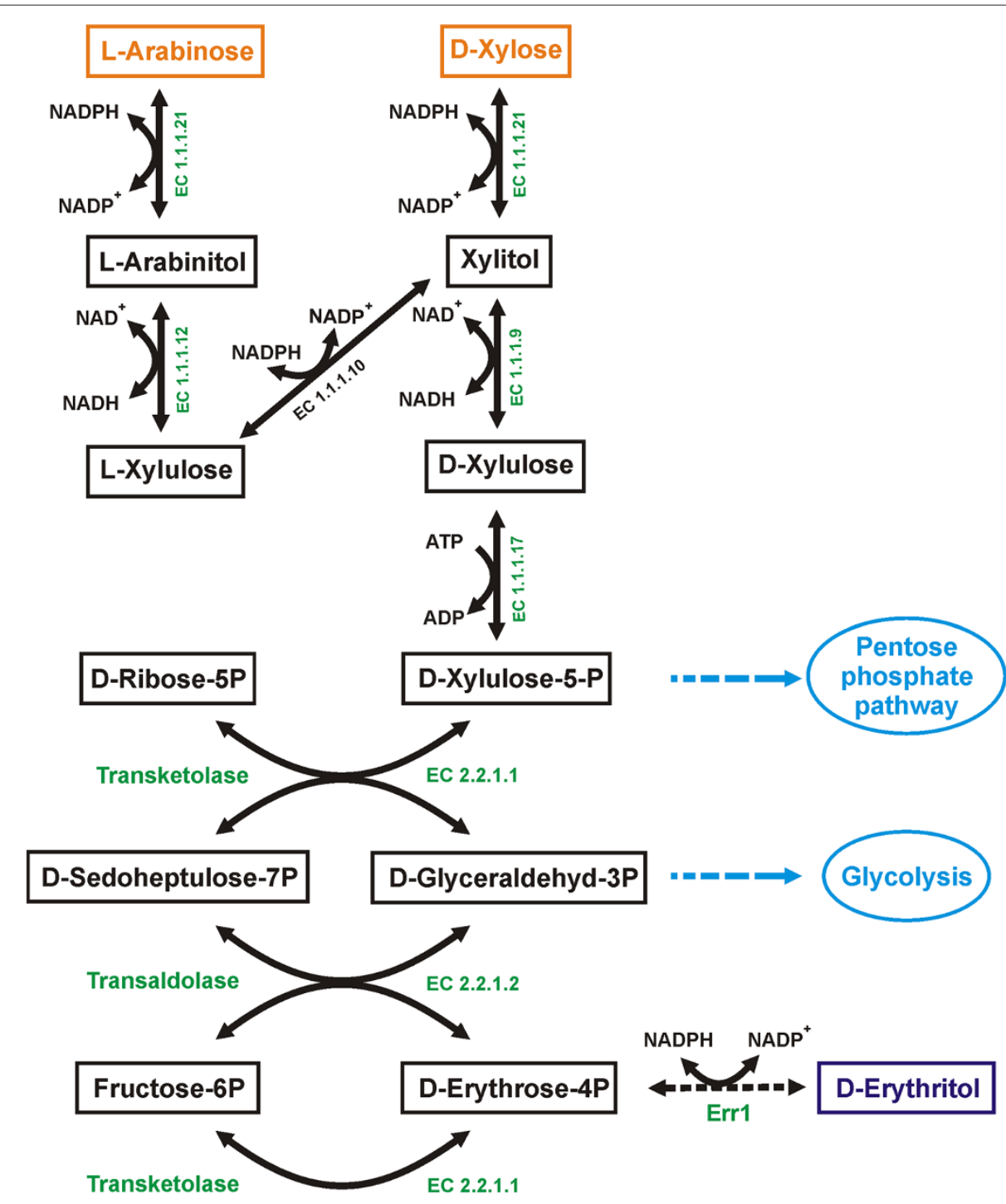

Figure 6 Schematic drawing of metabolic pathways of pentoses and erythritol in T. reesei. Metabolites are given in boxes. Monomeric sugars derived from hydrolytic lignocellulose degradation by T. reesei are given in orange. The target substance, erythritol, is given in purple. Enzyme names and EC numbers are given in green. Adjacent pathways are indicated in blue. Dashed arrows indicate (possible) involvement of more than one enzyme.

were optimized for decades now. For example, in 1999 for C. magnolia $6.9 \mathrm{~g} / \mathrm{l}$ erythritol formation was reported for the wild-type, while with mutant strains concentrations of up to $25 \mathrm{~g} / \mathrm{l}$ were obtained (Yang et al. 1999). Years later further process optimization led to a maximum final erythritol concentration of $200 \mathrm{~g} / \mathrm{l}$ if fed with $70 \%(\mathrm{w} / \mathrm{v})$ glucose supplemented with yeast extract (Koh et al. 2003). As D-glucose became the almost exclusively used substrate for erythritol production, usually the Dglucose to erythritol conversion (in \% (w/w)) is reported. Recently, for the C. magnolia NCIM 3470 mutant R23 a yield of 31.1\% was reported (Savergave et al. 2011), while with Trichosporonoides megachiliensis SN-G42 a conversion of $47 \%$ can be achieved (Sawada et al. 2009). However, the conversion of D-glucose to erythritol can not easily directly be compared to erythritol production from wheat straw due to the very different nature of these substrates. Anyway, the aim of this study was to provide proof-ofconcept for the synthesis of erythritol from wheat straw and additional metabolic engineering as described above. Subsequent strain screening might lead to competitive production levels in biomass-degrading fungi like $T$. ree$s e i$, with the advantage of using cheap and sustainable substrates.

Concluding this, in the present study we demonstrated that the production of erythritol on the renewable, nonfood substrate wheat straw, using T. reesei is possible. The alkaline organosolve pretreatment process used for 
the wheat straw is compatible for subsequent fungal growth and provides an easily utilizeable substrate. Moreover, strain modification by overexpression of err1 led to increased erythritol formation on this substrate.

\section{Additional file}

Additional file 1: Figure S1. Cultivation of Rut-C30 and an err1 overexpression strain on wheat straw. The Rut-C30 (blue bars) and the err 1 overexpression strain RPEC1 (red bars) were cultivated in bench-top bioreactors on pre-treated wheat straw. Samples were taken after 48 and 72 hours. (a) Sodium soluble protein concentration (given in $\mathrm{g} / \mathrm{l}$ cultivation broth) was measured in triplicates in cultivation broth samples after cell disruption to indicate biomass formation. Standard deviations were below 5\%. (b) Xylanase activity (given in U/I cultivation broth) was measured in triplicates in the cultivation supernatants. Standard deviations were below 5\%. (c) Erythritol concentration (given in $\mathrm{mg} / \mathrm{l}$ cultivation broth) was measured by GC in cultivation broth samples after cell disruption. Standard deviations were obtained from measurements in triplicates. (d) Transcript analysis of err (given as relative transcript ratio in logarithmic scale (lg)) was performed by qPCR using sar 1 and act as genes for data normalization and levels always refer to Rut-C30 cultivated for $48 \mathrm{~h}$ (as indicated by an asterisk). Standard deviations were obtained from measurements in triplicates. Biological experiments (cultivations) were performed in duplicates.

\section{Competing interests}

A European patent entitled 'Method for the production of erythritol' (no. EP20100183799, 5.4.2012) (Mach and Mach-Aigner 2012) was issued.

\section{Acknowledgments}

This study was supported by Annikki $\mathrm{GmbH}$, by two grants from the Austrian Science Fund (FWF): [P20192, P24851] given to RLM and ARMA, respectively, by an Innovative Project of Vienna University of Technology (Demo-Tech), and by a doctoral program of Vienna University of Technology (AB-Tec).

Received: 26 January 2014 Accepted: 28 January 2014

Published online: 29 May 2014

\section{References}

Acebal C, Castillon M, Estrada P, Mata I, Costa E, Aguado J, Romero D, Jimenez F (1986) Enhanced cellulase production from Trichoderma reesei QM 9414 on physically treated wheat straw. Appl Microbiol Biotechnol 24(3):218-223. doi:10.1007/BF00261540

Buchert J, Oksanen T, Pere J, Siika-aho M, Suurnkki A, Viikari L (1998) Applications of Trichoderma reesei enzymes in the pulp and paper industry. In: Harman G, Kubicek C (eds) Trichoderma \& Gliocladium, vol 2. Taylor \& Francis Ltd, London, UK, pp 343-357

Dashtban M, Kepka G, Seiboth B, Qin W (2013) Xylitol production by genetically engineered Trichoderma reesei strains using barley straw as feedstock. Appl Biochem Biotechnol 169(2):554-569. doi:10.1007/s12010-012-0008-y

Derntl C, Gudynaite-Savitch L, Calixte S, White T, Mach R, Mach-Aigner A (2013) Mutation of the xylanase regulator 1 causes a glucose blind hydrolase expressing phenotype in industrially used Trichoderma strains. Biotechnol Biofuels 6(1):62. doi:10.1186/1754-6834-6-62

Fackler K, Ters T, Ertl O, Messner K (2012) Method for lignin recovery. Patent WO/2012/027767

Galante YM, Monteverdi R, Inama S, Caldini C, De Conti A, Lavelli V, Bonomi F (1993) New applications of enzymes in wine making and olive oil production. Italian Biochem Soc Trans 4:34

Gruber F, Visser J, Kubicek CP, de Graaff LH (1990) The development of a heterologous transformation system for the cellulolytic fungus Trichoderma reesei based on a pyrG-negative mutant strain. Curr Genet 18(1):71-76

Hahn-Hägerdal B, Galbe M, Gorwa-Grauslund M, Lidén G, Zacchi G (2006) Bio-ethanol - the fuel of tomorrow from the residues of today. Trends Biotechnol 24(12):549-556

Himmel ME, Ding SY, Johnson DK, Adney WS, Nimlos MR, Brady JW, Foust TD (2007) Biomass recalcitrance: engineering plants and enzymes for biofuels production. Science 315(5813):804-807
Jovanovic B, Mach R, Mach-Aigner A (2013) Characterization of erythrose reductases from filamentous fungi. AMB Express 3(1):43. doi:10.1186/2191-0855-3-43

Kasumi T (1995) Fermentative production of polyols and utilization for food and other products in Japan. JARQ 29(1):49-55

Koh ES, Lee TH, Lee DY, Kim HJ, Ryu YW, Seo JH (2003) Scale-up of erythritol production by an osmophilic mutant of Candida magnoliae. Biotechnol Lett 25(24):2103-2105

Koo H, Ueda M, Wakida T, Yoshimura Y, Igarashi T (1994) Cellulase treatment of cotton fabrics. Text Res J 64(2):70-74. doi:10.1177/004051759406400202

Kuhls K, Lieckfeldt E, Samuels GJ, Kovacs W, Meyer W, Petrini O, Gams W, Börner T, Kubicek CP (1996) Molecular evidence that the asexual industrial fungus Trichoderma reesei is a clonal derivative of the ascomycete Hypocrea jecorina. PNAS 93(15):7755-7760

Kumar A, Lepola M, Purtell C (1994) Enyme finishing of man-made cellulosic fabrics. Text Chem Color 26(10):25-28

Lanzarini G, Pifferi P (1989) Enzymes in the fruit juice industry. In: Cantarelli C, Lanzarini $\mathrm{G}$ (eds) Biotechnology applications in beverage production. Elsevier Applied Food Science Series, Springer Netherlands, pp 189-222. doi:10.1007/978-94-009-1113-0_13

Livesey G (2001) Tolerance of low-digestible carbohydrates: a general view. Br J Nutr 85:7-16

Mach R, Mach-Aigner A (2012) Method for the production of erythritol. Patent EP20100183799

Mach R, Zeilinger S (1998) Genetic transformation of Trichoderma and Gliocladium. In: Kubicek CP, Harman GE (eds) Trichoderma \& Gliocladium. Taylor \& Francis Ltd, London, UK, pp 225-224

Mach R, Schindler M, Kubicek CP (1994) Transformation of Trichoderma reesei based on hygromycin B resistance using homologous expression signals. Curr Genet 25(6):567-570

Mandels M (1985) Applications of cellulases. Biochem Soc Trans 13(2):414-416

Martinez D, Berka RM, Henrissat B, Saloheimo M, Arvas M, Baker SE, Chapman J, Chertkov O, Coutinho PM, Cullen D, Danchin EGJ, Grigoriev IV, Harris P, Jackson M, Kubicek CP, Han CS, Ho I, Larrondo LF, Leon ALd, Magnuson JK, Merino S, Misra M, Nelson B, Putnam N, Robbertse B, Salamov AA, Schmoll M, Terry A, Thayer N, Westerholm-Parvinen A, et al. (2008) Genome sequencing and analysis of the biomass-degrading fungus Trichoderma reesei (syn. Hypocrea jecorina). Nat Biotechnol 26(5):553-560

Montenecourt BS, Eveleigh DE (1979) Selective screening methods for the isolation of high yielding cellulase mutants of Trichoderma reesei. In: Brown RD, Jurasek L (eds) Hydrolysis of cellulose: Mechanisms of enzymatic and acid catalysis. American Chemical Society, Washington, D. C., pp 289-301. doi:10.1021/ba-1979-0181.ch014

Moon HJ, Jeya M, Kim IW, Lee JK (2010) Biotechnological production of erythritol and its applications. Appl Microbiol Biotechnol 86(4): 1017-1025. doi:10.1007/s00253-010-2496-4

Munro I, Bernt W, Borzelleca J, Flamm G, Lynch B, Kennepohl E, Br E, Modderman J (1998) Erythritol: an interpretive summary of biochemical, metabolic, toxicological and clinical data. Food Chem Toxicol 36(12):1139-1174. http://dx.doi.org/10.1016/S0278-6915(98)00091-X

Noé P, Chevalier J, Mors F, Comtat J (1986) Action of xylanases on chemical pulp fibers part II : Enzymatic beating. J Wood Chem Technol 6(2):167-184. doi:10.1080/02773818608085222

Pedersen GP, Screws GA, Cereoni DA (1992) Biopolishing of cellulosic fabrics. Can Text J Dec: $31-35$

Peterson R, Nevalainen H (2012) Trichoderma reesei RUT-C30 thirty years of strain improvement. Microbiology 158(1):58-68. doi:10.1099/mic.0.054031-0

Pfaffl MW (2001) A new mathematical model for relative quantification in real-time RT-PCR. Nucleic Acids Res 29(9):45

Punt PJ, Oliver RP, Dingemanse MA, Pouwels PH, van den Hondel CA (1987) Transformation of Aspergillus based on the hygromycin B resistance marker from Escherichia coli. Gene 56(1):117-124. doi:10.1016/03781119(87)90164-8

Ragauskas AJ, Williams CK, Davison BH, Britovsek G, Cairney J, Eckert CA, Frederick WJ, Hallett JP, Leak DJ, Liotta CL, Mielenz JR, Murphy R, Templer R, Tschaplinski T (2006) The path forward for biofuels and biomaterials. Science 311 (5760):484-489. doi:10.1126/science.1114736

Rymowicz W, Rywińska A, Marcinkiewicz M (2009) High-yield production of erythritol from raw glycerol in fed-batch cultures of Yarrowia lipolytica. Biotechnol Lett 31(3):377-380. doi:10.1007/s10529-008-9884-1 
Ryu YW, Park CY, Park JB, Kim SY, Seo JH (2000) Optimization of erythritol production by Candida magnoliae in fed-batch culture. J Ind Microbiol Biotechnol 25(2): 100-103. doi:10.1038/sj.jim.7000039

Savergave LS, Gadre RV, Vaidya BK, Narayanan K (2011) Strain improvement and statistical media optimization for enhanced erythritol production with minimal by-products from Candida magnoliae mutant R23. Biochem Eng J 55(2):92-100. http://dx.doi.org/10.1016/j.bej.2011.03.009

Sawada K, Taki A, Yamakawa T, Seki M (2009) Key role for transketolase activity in erythritol production by Trichosporonoides megachiliensis SN-G42. J Biosci Bioeng 108(5):385-390. http://dx.doi.org/10.1016/j.jbiosc.2009.05. 008

Steiger M, Vitikainen M, Uskonen P, Brunner K, Adam G, Pakula T, Penttilä M, Saloheimo M, Mach R, Mach-Aigner AR (2011) Transformation system for Hypocrea jecorina (Trichoderma reesei) that favors homologous integration and employs reusable bidirectionally selectable markers. Appl Environ Microbiol 77(1):114-121. doi:10.1128/AEM.02100-10

Steiger MG, Mach RL, Mach-Aigner AR (2010) An accurate normalization strategy for RT-qPCR in Hypocrea jecorina (Trichoderma reesei). J Biotech 145(1):30-37. doi:10.1016/j.jbiotec.2009.10.012

Te'o V, Bergquist P, Nevalainen K (2002) Biolistic transformation of Trichoderma reesei using the bio-rad seven barrels hepta adaptor system. J Microbiol Meth 51(3):393-399. http://dx.doi.org/10.1016/S0167-7012(02)00126-4

Walsh G, Power R, Headon D (1993) Enzymes in the animal-feed industry. Trends Biotechnol 11(10):424-430

Welt T, Dinus R (1995) Enzymatic deinking - a review. Prog Paper Recycl 4(2):36-47

Yang SW, Park JB, Han NS, Ryu YW, Seo JH (1999) Production of erythritol from glucose by an osmophilic mutant of Candida magnoliae. Biotechnol Lett 21:887-890

doi:10.1186/s13568-014-0034-y

Cite this article as: Jovanović et al:: Erythritol production on wheat straw using Trichoderma reesei. AMB Express 2014 4:34.

\section{Submit your manuscript to a SpringerOpen ${ }^{\circ}$ journal and benefit from:}

- Convenient online submission

- Rigorous peer review

- Immediate publication on acceptance

- Open access: articles freely available online

- High visibility within the field

- Retaining the copyright to your article

Submit your next manuscript at $\gg$ springeropen.com 